Bull. Chem. Soc. Ethiop. 2014, 28(1), 37-44.

Printed in Ethiopia

DOI: http://dx.doi.org/10.4314/bcse.v28i1.5

ISSN 1011-3924

(c) 2014 Chemical Society of Ethiopia

\title{
DEVELOPMENT OF A HYDROTHERMAL METHOD TO SYNTHESIZE SPHERICAL ZNSE NANOPARTICLES: APPROPRIATE TEMPLATES FOR HOLLOW NANOSTRUCTURES
}

\author{
Soodabe Gharibe ${ }^{1 *}$, Shahrara Afshar ${ }^{2}$ and Leila Vafayi ${ }^{1}$ \\ ${ }^{1}$ Firoozkooh Branch, Islamic Azad University, Firoozkooh, Iran \\ ${ }^{2}$ Department of Chemistry, Iran University of Science and Technology, \\ 16846-13114 Tehran, Iran
}

(Received November 23, 2012; revised November 20, 2013)

\begin{abstract}
Hydrothermal method was used to synthesize pure ZnSe nanosphere materials. The effects of the reducing agent amount, the reaction time and temperature were investigated on the purity of ZnSe. Also, the effects of surfactants such as sodium dodecyl sulfate (SDS) (anionic) and cetyl trimethylammonium bromide (CTAB) (cationic) were studied on the morphology of $\mathrm{ZnSe}$. The prepared nanospheres were characterized using $\mathrm{XRD}$, SEM, TEM and UV-Vis spectroscopy. Through these techniques, it was found that the pure $\mathrm{ZnSe}$ nanoparticles have a zinc blend structure and in a spherical form with average diameter of $30 \mathrm{~nm}$.
\end{abstract}

KEY WORDS: ZnSe, Nanosphere, Hydrothermal, Surfactant

\section{INTRODUCTION}

In recent years, synthesis of nanostructured materials has attracted the attention of a large number of research groups. Also, these materials have been widely studied for their unique physical and chemical properties. The preparation of nanomaterials with controlled size, morphologies and size distribution is always potentially important in the synthesis of materials suitable for optoelectronic and luminescent applications [1-3].

As one of the most important II-VI group semiconductors, ZnSe with a room temperature bulk band gap of $2.7 \mathrm{eV}$, is a good candidate for short wavelength lasers and other optoelectronic devices such as blue-green laser diodes and turnable mid-IR laser sources [4-8].

Size, dimensionality and size distribution are known to play important roles in determining the physical and chemical properties of nanostructured materials $[9,10]$. It is difficult to control the size distribution and these results in a broad and profoundly red shifted photoluminescence emission. Hence, there is a need for developing a new approach to obtain monodispersed $\mathrm{ZnSe}$ nanoparticles [11].

Various methods such as molecular beam epitaxy, metalorganic chemical vapor deposition and organometallic vapor phase epitaxy have been used to synthesize $\mathrm{ZnSe}$ nanoparticles [2, 6, 12]. Solvothermal methods have also been developed for the synthesis of $\mathrm{ZnSe}$ and CdSe. The advantage of the solvothermal processes is that they required relatively low temperatures and pressures. However, organic solvents are usually harmful to the environment; therefore the nontoxic solvents would be used for achieve the products in a large scale. Recently, $\mathrm{ZnSe}$ nanostructure has been synthesized by using different hydrothermal methods [12].

This work aimed to synthesize $\mathrm{ZnSe}$ nanoparticles suitable as templates for fabricating hollow nanostructures. These materials can have a wonderful application in drug delivery and catalysis. In this work, we have reported the effects of the amount of reducing agent, the reaction time and temperature and the type of the surfactant for the preparation of pure $\mathrm{ZnSe}$ nanospheres by hydrothermal method.

*Corresponding author. E-mail: gharibeh@iaufb.ac.ir 


\section{EXPERIMENTAL}

All the reagents were analytical grade and purchased from Merck Company. Reagents were used without any further purification. In order to obtain a pure phase of monodispersed $\mathrm{ZnSe}$ nanospherical particles the synthesis conditions such as: the reducing agent amount, type of the surfactant, the reaction temperature and time have been optimized. The optimization conditions are reported in the following sections. It is noteworthy the $\mathrm{Zn}$ to Se molar ratio has been set to be 1 in all experiments.

\section{Synthesis of ZnSe nanosphere particles}

Optimization of the reaction temperature. $5 \mathrm{mmol} \mathrm{ZnCl}_{2}(98 \%), 5 \mathrm{mmol} \mathrm{Na}_{2} \mathrm{SeO}_{3} .5 \mathrm{H}_{2} \mathrm{O}(97 \%)$ and $10 \mathrm{~mL} \mathrm{~N}_{2} \mathrm{H}_{4} \cdot \mathrm{H}_{2} \mathrm{O}(80 \%)\left(\mathrm{Na}_{2} \mathrm{SeO}_{3} \cdot 5 \mathrm{H}_{2} \mathrm{O}\right.$ to $\mathrm{N}_{2} \mathrm{H}_{4} \cdot \mathrm{H}_{2} \mathrm{O}$ molar ratio was equal to 0.025$)$ were sequentially added to $40 \mathrm{~mL}$ deionized water under sonication for $3 \mathrm{~h}$ using an ultrasound cleaner (VGT-1860QTD, $42 \mathrm{kHz}, 150 \mathrm{~W}$ ). The mixture was transferred into an autoclave, sealed and in different experiments was kept at $80,100,130,150$ and $160{ }^{\circ} \mathrm{C}$, respectively, for 8 h. After cooling the system to room temperature, the product was separated by centrifugation, washed with absolute ethanol and deionized water several times, and then dried under vacuum at $60{ }^{\circ} \mathrm{C}$ for $10 \mathrm{~h}$.

Optimization of the amount of hydrazine hydrate. The process was the same as in the previous section, using $5 \mathrm{mmol} \mathrm{ZnCl}_{2}, 5 \mathrm{mmol} \mathrm{Na}_{2} \mathrm{SeO}_{3} \cdot 5 \mathrm{H}_{2} \mathrm{O}$ and $\mathrm{N}_{2} \mathrm{H}_{4} \cdot \mathrm{H}_{2} \mathrm{O}$, which in different experiments $\mathrm{Na}_{2} \mathrm{SeO}_{3} .5 \mathrm{H}_{2} \mathrm{O}$ to hydrazine hydrate molar ratio was chosen to be equal to 0.025 $(10 \mathrm{~mL}), 0.05(5 \mathrm{~mL})$ and $0.0625(4 \mathrm{~mL})$, respectively. The reaction temperature and reaction time in the autoclave were $160{ }^{\circ} \mathrm{C}$ and $8 \mathrm{~h}$, respectively.

Optimization of the reaction time. In order to find the optimum time, the reaction in previous section was carried on at $160{ }^{\circ} \mathrm{C}$ for $2,4,6,7$ and $8 \mathrm{~h}$. Since the time required for the reaction was found to be $8 \mathrm{~h}$, to prevent repeating, we have reported only the reaction times of 7 and $8 \mathrm{~h}$ durations in the following sections.

\section{Synthesis of ZnSe nanospheres with SDS and CTAB surfactants}

In a typical synthesis, $5 \mathrm{mmol} \mathrm{ZnCl}_{2}$ was added to $20 \mathrm{~mL}$ of deionized water and sonicated for 15 min. Then solution of surfactants with $\mathrm{ZnCl}_{2}$ to SDS or CTAB ratio equal to 1 prepared in 20 $\mathrm{mL}$ of deionized water and was added slowly to $\mathrm{ZnCl}_{2}$ solution under sonication. Then, $5 \mathrm{mmol}$ $\mathrm{Na}_{2} \mathrm{SeO}_{3} \cdot 5 \mathrm{H}_{2} \mathrm{O}$ and $5 \mathrm{~mL} \mathrm{~N} \mathrm{H}_{4} \cdot \mathrm{H}_{2} \mathrm{O}(80 \%)$ were added and sonicated for $3 \mathrm{~h}$. The mixture was transferred into an autoclave, sealed and kept at $160{ }^{\circ} \mathrm{C}$ for $8 \mathrm{~h}$. After cooling the system to room temperature, the product was separated by centrifugation, washed with absolute ethanol and deionized water for several times, and then dried under vacuum at $60{ }^{\circ} \mathrm{C}$ for $10 \mathrm{~h}$.

\section{Characterization}

Having been purified, the crystal phase and particle size of the synthesized products were characterized by X-ray diffraction (XRD) using FK60-04 with $\mathrm{Cu} \mathrm{K \alpha}$ radiation $(\lambda=1.54 \AA$ ), and with instrumental setting of $35 \mathrm{kV}$ and $20 \mathrm{~mA}$. The morphology of the nanostructures was observed by emission scanning electron microscopy (SEM, Philips-XL $\varphi 30$ ) and transmission electron microscopy (TEM, Philips-CM120). UV-Vis spectra of the ZnSe nanosphere were recorded by MPC-2200, UV2550 UV-Vis spectrophotometer in the wavelength range of 300 to $600 \mathrm{~nm}$. Accessories used in this type of UV-Vis analysis are opal glass and an integrating sphere. The opal glass method involves the placement of a scattering board behind the sample, 
resulting in the equalization of scattering coefficients of the reference side and sample side. The integrating sphere method involves a barium sulfate-coated sphere that draws the scattered light, allowing all the light to reach the detector. Since light cannot penetrate opaque samples, it is reflected on the surface of the samples.

\section{RESULTS AND DISCUSSION}

In this work, hydrazine hydrate was used as reducing agent. The XRD patterns of ZnSe nanoparticles prepared at various temperatures are shown in Figure 1. During the experiments it was found that when the reaction is running for $8 \mathrm{~h}$ at less than $100^{\circ} \mathrm{C}$ the $\mathrm{ZnSe}$ is not produced and the products are $\mathrm{ZnO}$ and black powder of Se. Figure 1a shows the XRD patterns of the obtained products at $80{ }^{\circ} \mathrm{C}$. In these patterns all the diffraction peaks can be well indexed to Se and $\mathrm{ZnO}$ phases (JCPDS, No. 38-0768 and 36-1451, respectively). This means that hydrazine hydrate is not acting as a reductant for reducing the $\mathrm{SeO}_{3}{ }^{2-}$ to $\mathrm{Se}^{2-}$ at $80{ }^{\circ} \mathrm{C}$ and in this condition the hydrazine hydrate has reduced $\mathrm{SeO}_{3}{ }^{2-}$ to Se according to the reaction 1 .

$\mathrm{SeO}_{3}{ }^{2-}+\mathrm{N}_{2} \mathrm{H}_{5}{ }^{+} \rightarrow \mathrm{Se}+\mathrm{N}_{2}+\mathrm{OH}^{-}+2 \mathrm{H}_{2} \mathrm{O}$

A weak new peak is appeared at diffraction degree about $27.28^{\circ}$ when the temperature increased to $100{ }^{\circ} \mathrm{C}$ (Figure 1b). It may be due to the presence of $\mathrm{ZnSe}$ phase in the product. This means that the reduction of $\mathrm{SeO}_{3}{ }^{2-}$ to $\mathrm{Se}^{2-}$ ions by the hydrazine hydrate has been started at $100{ }^{\circ} \mathrm{C}$. When the temperature increased to $110-150{ }^{\circ} \mathrm{C}, \mathrm{Se}, \mathrm{ZnO}$ and $\mathrm{ZnSe}$ were obtained as reaction products (Figures $1 \mathrm{c}$ and $1 \mathrm{~d}$ ). In these conditions three clear peaks are appeared at diffraction degrees $27.28^{\circ}, 45.23^{\circ}$ and $53.58^{\circ}$, which can be well indexed to cubic zinc blend ZnSe (JCPDS, No. 37-1463).

The pure $\mathrm{ZnSe}$ nanoparticles can be obtained only when the temperature is above $150{ }^{\circ} \mathrm{C}$. Figure 1e shows the XRD pattern of the pure $\mathrm{ZnSe}$ nanoparticles at $160^{\circ} \mathrm{C}$. No other crystalline phase was found in the XRD pattern. Therefore it can be concluded that the pure $\mathrm{ZnSe}$ nanoparticles can be synthesized only when the temperature is over $150{ }^{\circ} \mathrm{C}$.

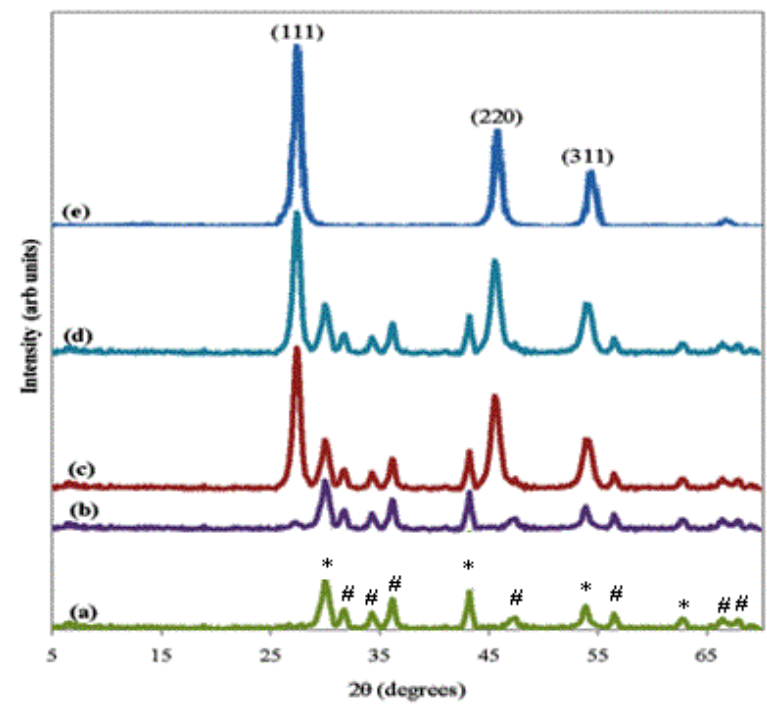

Figure 1. XRD patterns of the prepared samples at the temperatures of: (a) $80(\mathrm{ZnO}=\#, \mathrm{Se}=*)$, (b) 100 , (c) 130 , (d) 150 and (e) $160{ }^{\circ} \mathrm{C}$.

Bull. Chem. Soc. Ethiop. 2014, 28(1) 
Decreasing of hydrazine hydrate $(80 \%)$ from 10 to $5 \mathrm{~mL}$ had no effects on the purity of the $\mathrm{ZnSe}$ phase (Figure 2a). Whereas, when using less than $5 \mathrm{~mL}$ of hydrazine hydrate, at $160{ }^{\circ} \mathrm{C}$ for $8 \mathrm{~h}, \mathrm{Se}$ and $\mathrm{ZnO}$ phases were reappeared (Figure 2). The results showed that it is required to use $5 \mathrm{mmol}$ of $\mathrm{Na}_{2} \mathrm{SeO}_{3} \cdot 5 \mathrm{H}_{2} \mathrm{O}(97 \%)$ as starting material at least $5 \mathrm{~mL}$ of hydrazine hydrate $(80 \%)$ in order to prepare pure $\mathrm{ZnSe}$ at $160^{\circ} \mathrm{C}$ for $8 \mathrm{~h}$.

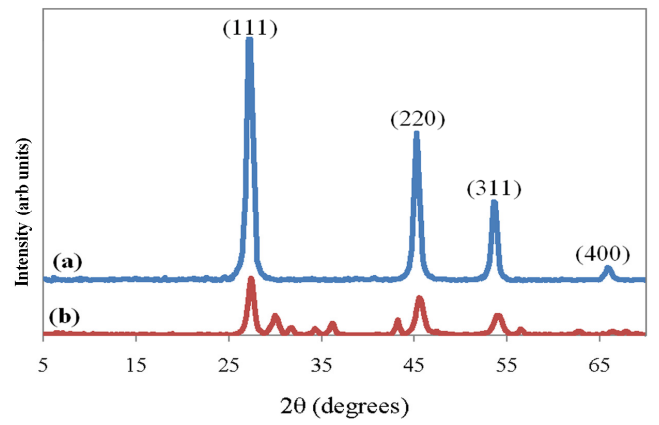

Figure 2. XRD patterns of the prepared $\mathrm{ZnSe}$ with: (a) $5 \mathrm{~mL}$ and (b) $4 \mathrm{~mL}$ hydrazine hydrate.

In order to find the optimum time, the reaction was carried on at $160{ }^{\circ} \mathrm{C}$ for $2,4,6,7$ and 8 h. Since the time required for the reaction was found to be $8 \mathrm{~h}$, to prevent repeating, here we are reporting only the reaction time of 7 and $8 \mathrm{~h}$ durations. Figure 3 shows the XRD pattern of the prepared $\mathrm{ZnSe}$ with $5 \mathrm{~mL}$ hydrazine hydrates at $160^{\circ} \mathrm{C}$ for $7 \mathrm{~h}$. It can be seen that $\mathrm{ZnO}$ and Se particles have been appeared again after decreasing the reaction time from 8 to $7 \mathrm{~h}$. Therefore, the pure $\mathrm{ZnSe}$ nanoparticles can be obtained only when the temperature is above $150{ }^{\circ} \mathrm{C}$ and the reaction duration is $8 \mathrm{~h}$, while the hydrazine hydrate to $\mathrm{Na}_{2} \mathrm{SeO}_{3} .5 \mathrm{H}_{2} \mathrm{O}$ molar ratio is equal to 0.05 .

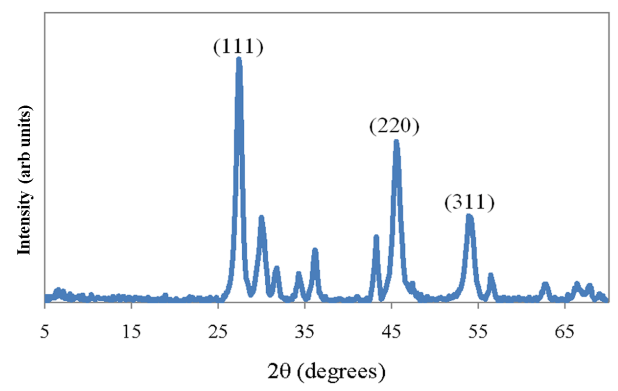

Figure 3. XRD pattern of the prepared $\mathrm{ZnSe}$ for $7 \mathrm{~h}$.

The XRD patterns of pure ZnSe nanoparticles prepared with and without surfactant in optimum conditions are shown in Figure 4. All peaks can be well indexed to cubic zinc blend. No other crystalline phase was found in the XRD pattern. Figure 4a shows the XRD pattern of the $\mathrm{ZnSe}$ nanospheres prepared without the surfactant. The lattice constant obtained from XRD data was $a=5.669 \AA$, which is consistent with that of the bulk cubic ZnSe (JCPDS, No. 371463 Card, $\mathrm{a}=5.66882(8) \AA$ A). Figures $4 \mathrm{~b}$ and $4 \mathrm{c}$ show the XRD patterns of the $\mathrm{ZnSe}$ nanospheres prepared with SDS and CTAB surfactants, respectively. In these patterns all diffraction peaks can be indexed to cubic zinc blend (JCPDS, No. 05-0522, a = 5.667 $⿱$ ). The lattice constant of the ZnSe nanospheres prepared with SDS and CTAB surfactants was calculated using XRD data and were 5.663 and $5.649 \AA$, respectively (standard deviation = 
0.01). These results indicate that the lattice parameter of the nanoparticles are smaller than those of the bulk crystalline $\mathrm{ZnSe}(\mathrm{a}=5.667 \AA)$. It is shown that in most reported nanoparticles, the lattice constants often decrease with decreasing the particle size [12-14]. The different synthesis conditions with products are listed in Table 1.

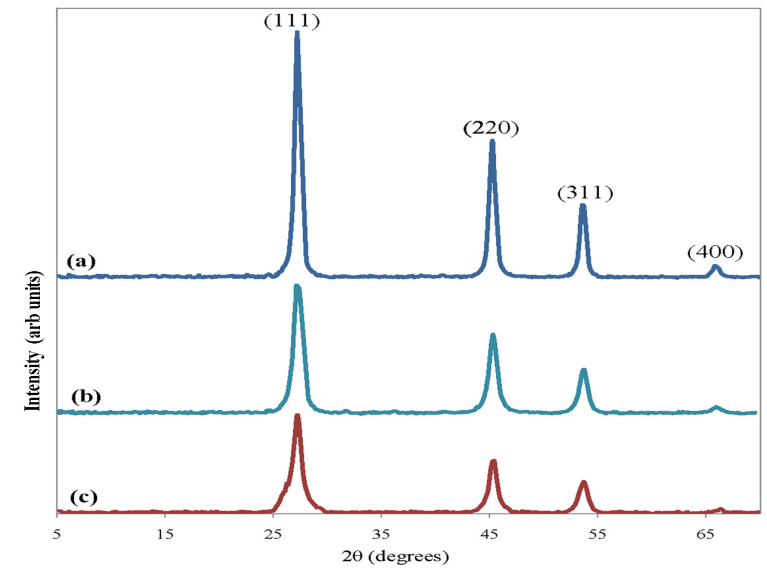

Figure 4. XRD patterns of pure ZnSe prepared: (a) without surfactant, (b) with SDS surfactant and (c) with CTAB surfactant.
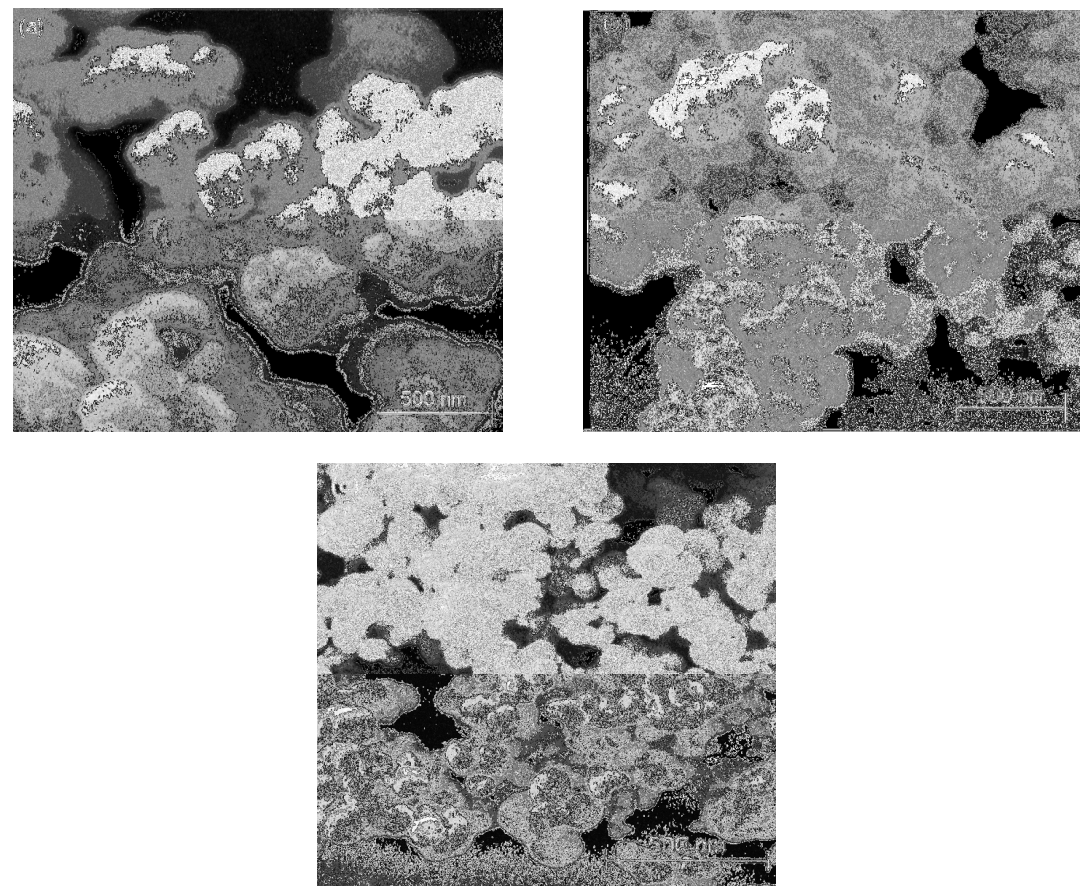

Figure 5. SEM images of ZnSe nanospheres prepared: (a) without surfactant, (b) with SDS surfactant and (c) with CTAB surfactant.

Bull. Chem. Soc. Ethiop. 2014, 28(1) 
The morphology of the products was observed by SEM and TEM images. The SEM images of the synthesized products are shown in Figures 5(a-c). These images clearly demonstrate that the products are spherical. It can also be seen that there is a well size distribution in all products. The grain size distribution of $\mathrm{ZnSe}$ prepared with $\mathrm{Zn} / \mathrm{Se}=1$ is narrow and is consistent with the unimodal normal distribution [15]. This narrowness may also be due to the effect of sonication before transferring into autoclave. The SEM observations show that the samples prepared with surfactants are less aggregated. This can be due to coating of inorganic core by the surfactant, which prevents the nanoparticles to aggregate. It is proved that the prevention of aggregation of nanoparticles in the presence of the surfactant is more effective when the surfactant has a long and branched chain structure $[9,16]$. The SEM images show that the ZnSe prepared with CTAB surfactant is less aggregated because of its longer and branched chain structure. The energy dispersive X-ray (EDAX) analyses of prepared samples confirm that the $\mathrm{Zn}$ and Se elemental ratio is 1:1 for all $\mathrm{ZnSe}$ samples (Figure 6).

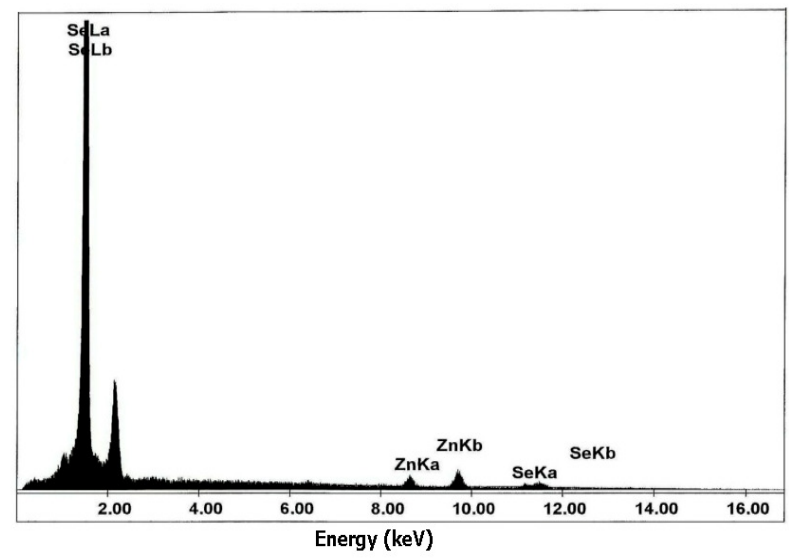

Figure 6. EDX spectrum of ZnSe nanospheres.

The TEM images of the synthesized products are shown in Figures 7(a-c). It is clear that the prepared ZnSe nanoparticles using CTAB surfactant are spherical with average diameter of 30 $\mathrm{nm}$. So far, ZnSe nanostructures with different morphologies have been synthesized. In 2008, Yang et al. [18] prepared flower-like ZnSe microstructure and Shi et al. [9] synthesized ZnSe nanodonuts by hydrothermal method. ZnSe guantum dots were synthesized by Jiao et al. [7] and Jana et al. [3] using hydrothermal and solvothermal methods, respectively. These samples are not appropriate templates for hollow nanostructures used in drug delivery. Quantum dots have smaller size than those of most drugs. The other morphologies cannot create uniform spherical hollow structures. In this work, we have prepared a pure sample of nanosphere ZnSe. The nanoparticles with these characteristics are appropriate templates for hollow nanostructures and these hollow nanostructures will show a wonderful application in drug delivery and catalysis. The optical properties of the semiconductor nanomaterials depend on the size and the shape of the particles. UV-Vis spectra of ZnSe samples are shown in Figure 8. The optical absorption spectrum can be used to estimate the bandgap of the semiconductors. The band gap for the prepared $\mathrm{ZnSe}$ samples was calculated to be 2.95 and $2.75 \mathrm{eV}$, with and without surfactant, respectively. The band gap values are obtained by following equation: $E=h c / \lambda$, where $\lambda$ is estimated from shoulder or peak of the spectra correspond to the fundamental absorption edges in the samples, $\mathrm{h}$ is Planck constant, $\mathrm{c}$ is the speed of light and $\mathrm{E}$ is energy $\left(1 \mathrm{eV}=1.602 \times 10^{-19}\right.$ J). 

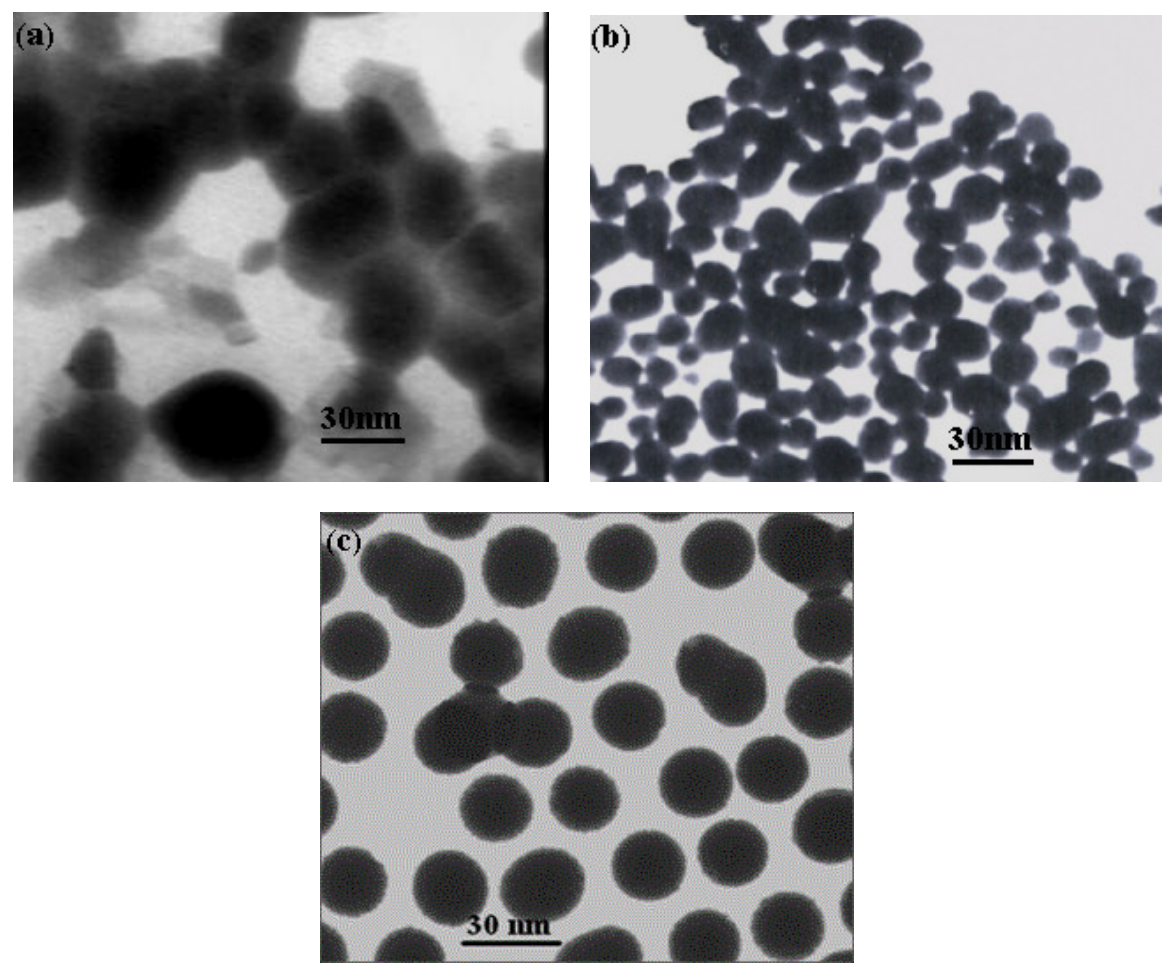

Figure 7. TEM image of prepared ZnSe nanospheres using CTAB surfactant.
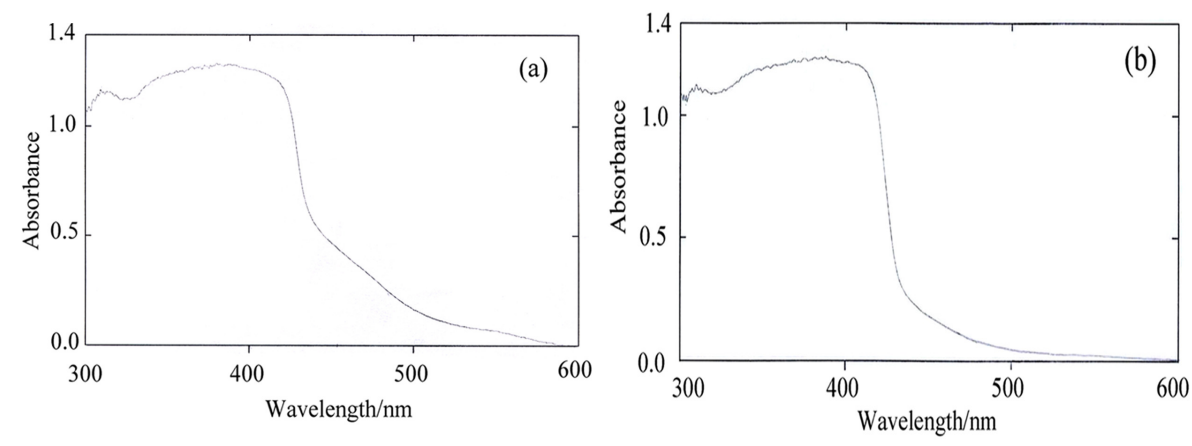

Figure 8. The UV-Vis spectra of ZnSe prepared: (a) without and (b) with CTAB surfactant.

The absorption edge shows a blue shift to higher energies as compared with the bulk $\mathrm{ZnSe}$ $(2.7 \mathrm{eV})$. This is due to the fact that smaller particles have larger band gaps and absorb at shorter wavelengths $[10,17,18]$. Investigation of the spectra reveals that the synthesized ZnSe using CTAB surfactant (Figure 8b) has a sharper absorption edge. This is consistent with the SEM images and indicates that the synthesized particles can be considered to be monodispersed. 


\section{CONCLUSIONS}

ZnSe spherical nanoparticles have been synthesized using hydrothermal method. The results exhibited that the ZnSe nanospheres prepared using CTAB surfactant are spherical and can be considered as monodispersed particles. The nanoparticles with monodispersed nanosphere characteristics are appropriate templates for hollow nanostructures. Therefore, these hollow nanostructures via removal of $\mathrm{ZnSe}$ attract the attention of many researchers in applying them in drug delivery and catalysis.

Table 1. Different synthesis conditions with products.

\begin{tabular}{|c|c|c|c|c|c|c|}
\hline Samples & $\begin{array}{c}\text { Sources of } \mathrm{Zn} \\
\text { and Se }\end{array}$ & $\begin{array}{c}\text { Type of } \\
\text { surfactant }\end{array}$ & $\begin{array}{c}\text { Amount of } \\
\text { reducing agent }\end{array}$ & $\begin{array}{c}\text { Reaction } \\
\text { temperature }\end{array}$ & $\begin{array}{c}\text { Reaction } \\
\text { time (h) }\end{array}$ & products \\
\hline $\mathbf{1}$ & $\mathrm{ZnCl}_{2}, \mathrm{Na}_{2} \mathrm{SeO}_{3}$ & - & $10 \mathrm{~mL}$ & $80^{\circ} \mathrm{C}$ & 8 & $\mathrm{Se}, \mathrm{ZnO}$ \\
\hline $\mathbf{2}$ & $\mathrm{ZnCl}_{2}, \mathrm{Na}_{2} \mathrm{SeO}_{3}$ & - & $10 \mathrm{~mL}$ & $10{ }^{\circ} \mathrm{C}$ & 8 & $\mathrm{Se}, \mathrm{ZnO}, \mathrm{ZnSe}$ \\
\hline $\mathbf{3}$ & $\mathrm{ZnCl}_{2}, \mathrm{Na}_{2} \mathrm{SeO}_{3}$ & - & $10 \mathrm{~mL}$ & $130^{\circ} \mathrm{C}$ & 8 & $\mathrm{ZnSe}, \mathrm{Se}, \mathrm{ZnO}$ \\
\hline $\mathbf{4}$ & $\mathrm{ZnCl}_{2}, \mathrm{Na}_{2} \mathrm{SeO}_{3}$ & - & $10 \mathrm{~mL}$ & $150^{\circ} \mathrm{C}$ & 8 & $\mathrm{ZnSe}, \mathrm{Se}, \mathrm{ZnO}$ \\
\hline $\mathbf{5}$ & $\mathrm{ZnCl}_{2}, \mathrm{Na}_{2} \mathrm{SeO}_{3}$ & - & $10 \mathrm{~mL}$ & $160^{\circ} \mathrm{C}$ & 8 & Pure $\mathrm{ZnSe}$ \\
\hline $\mathbf{6}$ & $\mathrm{ZnCl}_{2}, \mathrm{Na}_{2} \mathrm{SeO}_{3}$ & - & $5 \mathrm{~mL}$ & $160^{\circ} \mathrm{C}$ & 8 & Pure $\mathrm{ZnSe}$ \\
\hline $\mathbf{7}$ & $\mathrm{ZnCl}_{2}, \mathrm{Na}_{2} \mathrm{SeO}_{3}$ & - & $4 \mathrm{~mL}$ & $160^{\circ} \mathrm{C}$ & 8 & $\mathrm{ZnSe}, \mathrm{Se}, \mathrm{ZnO}$ \\
\hline $\mathbf{8}$ & $\mathrm{ZnCl}_{2}, \mathrm{Na}_{2} \mathrm{SeO}_{3}$ & - & $5 \mathrm{~mL}$ & $160^{\circ} \mathrm{C}$ & 7 & $\mathrm{ZnSe}, \mathrm{Se}, \mathrm{ZnO}$ \\
\hline $\mathbf{9}$ & $\mathrm{ZnCl}_{2}, \mathrm{Na}_{2} \mathrm{SeO}_{3}$ & $\mathrm{SDS}$ & $5 \mathrm{~mL}$ & $160^{\circ} \mathrm{C}$ & 8 & Pure $\mathrm{ZnSe}$ \\
\hline $\mathbf{1 0}$ & $\mathrm{ZnCl}_{2}, \mathrm{Na}_{2} \mathrm{SeO}_{3}$ & $\mathrm{CTAB}$ & $5 \mathrm{~mL}$ & $160^{\circ} \mathrm{C}$ & 8 & Pure $\mathrm{ZnSe}$ \\
\hline
\end{tabular}

\section{REFERENCES}

1. Pradeep, V.; Kirtiva, V.A.; Vishwakarma, O.P.; Singh, A.K.; Meera, R.A. J. Pure Appl. \& Ind. Phys. 2011, 1, 212.

2. Yang, J.; Wang, G.; Liu, H.; Park, J.; Chen, X. Mater. Chem. Phys. 2009, 115, 204.

3. Jana, S.; Baek, I.C.; Lim, M.A.; Seok, S.I. J. Colloid Interface Sci. 2008, 322, 437.

4. Jose', M.V.; Amber, A.M.; John, B.P.; Yann, F.; Tosifa, A.M.; Vichiksha, S.; Nathaniel, C.C.; Brian, A.A.; Antonio, C.R.; Gennady, A.S.; James, R.O.; Natalie, L.A.; Hugh, D.C.S.; Marek, O. J. Appl. Phys. 2011, 109, 07 B536.

5. Lee, S.Y.; Sabar, D.H. Sol. Sci. Technol. 2010, 18, 171.

6. Cheng, C.L.; Chen, Y.F. Chem. Phys. 2009, 115, 158.

7. Jiao, Y.; Yu, D.; Wang, Z.; Tang, K.; Sun, X. Mate. Lett. 2007, 61, 1541.

8. Jiang, C.; Zhang, W.; Zou, G.; Yu, W.; Qian, Y. Nanotechnol. 2005, 16, 551.

9. Shi, L.; Xu, Y.; Li, Q. Solid State Commun. 2008, 146, 384.

10. Lei, Z.; Wei, X.; Bi, S.; He, R. Mater. Lett. 2008, 62, 3694.

11. Deshpande, A.C.; Singh, S.B.; Abyaneh, M.K.; Pasricha, R.; Kulkarin, S.K. Mater. Lett. 2008, 62, 3803.

12. Jorgensen, J.E.; Jensen,T.R.; Hanson, J.C. J. Solid State. Chem. 2008, 181, 1925.

13. Qi, W.H.; Wang, M.P.; Su, Y.C. J. Mater. Sci. Lett. 2002, 21, 877.

14. Zhang, F.S.; Chan, W.; Spanier, H.E.; Apak, E.; Jin, Q.; Robinson, R.D.; Herman, I.P. Appl. Phys. Lett. 2002, 80, 127.

15. Gon, H.; Huang, H.; Wang, M.; Liu, K. Ceram. Int. 2007, 33, 1381.

16. Choy, W.C.H.; Xiong, S.; Sun, Y. J. Phys. D: Appl. Phys. 2009, 42, 125410.

17. Badr, Y.; Mahmoud, M.A. Spectrochim. Acta, Part A 2006, 65, 584.

18. Yang, Y.; Du, F.; Miao, C. Mater. Lett. 2008, 62, 1333. 